\title{
Commentary: One and done: The case for single-dose del Nido cardioplegia
}

\author{
Mark R. Helmers, MD, and Pavan Atluri, MD
}

\footnotetext{
From the Division of Cardiovascular Surgery, Department of Surgery, University of Pennsylvania, Philadelphia, $\mathrm{Pa}$.

Disclosures: Authors have nothing to disclose with regard to commercial support.

Received for publication Sept 3, 2019; revisions received Sept 3, 2019; accepted for publication Sept 3, 2019; available ahead of print Sept 21, 2019

Address for reprints: Pavan Atluri, MD, Division of Cardiovascular Surgery, Hospital of the University of Pennsylvania, 3400 Spruce St, 6 Silverstein Pavilion, Philadelphia, PA (E-mail: Pavan.Atluri@uphs.upenn.edu). J Thorac Cardiovasc Surg 2020;160:1203-4 $0022-5223 / \$ 36.00$

Copyright (C) 2019 by The American Association for Thoracic Surgery https://doi.org/10.1016/j.jtcvs.2019.09.020
}

Since Melrose's initial description of hyperkalemic arrest in $1955,{ }^{1}$ there has been considerable study and debate to determine the optimum cardioplegia strategy. ${ }^{2-4}$ The perfect cardioplegia solution must rapidly induce diastolic arrest and protect against injury from global ischemia and reperfusion while being easily reversible and nontoxic. ${ }^{5}$ Histidine-tryptophan-ketoglutarate (HTK) cardioplegia and del Nido (DN) cardioplegia are 2 solutions that have garnered a great deal of interest and use due to their ability to provide myocardial protection for 90 to 120 minutes without redosing. ${ }^{6,7}$ Several randomized controlled trials have compared these solutions with traditional multidose cardioplegia $^{2-4,8-11}$; however, they have been limited by small sample sizes.

In this issue of the Journal, Gambardella and colleagues $^{12}$ report their results of a meta-analysis of 10 randomized controlled trials and 13 propensity-score matched cohort trials comparing single-dose HTK and DN with traditional multidose blood or crystalloid cardioplegia. When compared with multidose cardioplegia, DN reduced both ischemic time (mean difference -7.18 minutes [-12.52 to -1.84$], P<.01$ ) and bypass time (mean difference -10.44 minutes $[-18.99$ to -1.88$], P<.01$ ), as well as incidence of reperfusion fibrillation (odds ratio 0.16 [0.05-0.54], $P<.01]$ and postoperative cardiac enzyme leak (standard mean difference -0.17 [-0.29 to 0.05$]$, $P<.01)$. Interestingly, HTK did not offer these benefits but rather increased bypass time and reperfusion fibrillation.

Furthermore, there was no difference in mortality and myocardial infarction between groups. Concern exists among some surgeons regarding the ability to achieve a complete and uniform distribution of cardioplegia with a single dose in patients with severe coronary artery disease. ${ }^{13}$ Multivariable meta-regression performed by the authors demonstrated that this similarity in mortality rates was not only independent of type of surgery (coronary vs valve)

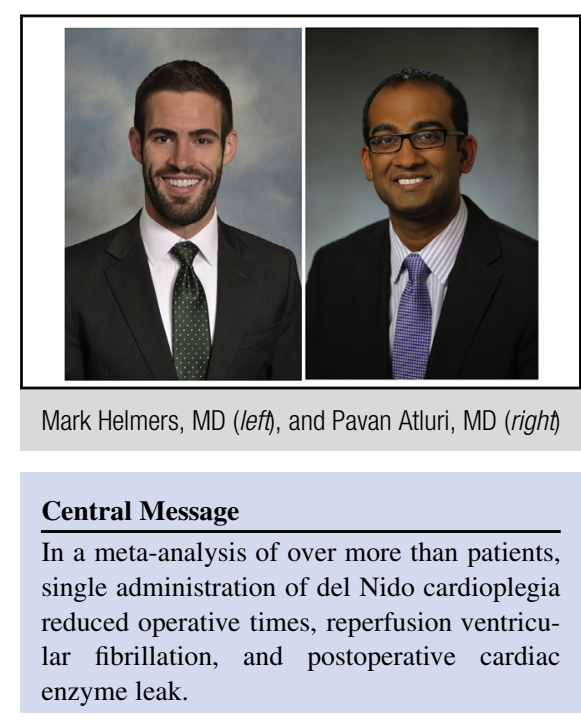

See Article page 1195.

but also of surgical approach (minimally invasive vs full sternotomy) and left ventricular ejection fraction.

While the authors performed an excellent analysis, there are important limitations of the original studies that deserve consideration when applying these findings to clinical practice. Patients with low ejection fraction, previous cardiac surgery, preoperative inotropic or mechanic support, urgent or emergent operative status, and severe coronary artery disease or preoperative myocardial infarction were often excluded. As a result, operative times were often relatively short. Furthermore, as the authors astutely point out, even despite the large sample size gained by the meta-analysis, the study is likely still underpowered to detect differences in mortality.

Nevertheless, the results are exciting and suggest that DN cardioplegia is here to stay. Certainly single-dose cardioplegia streamlines surgical workflow. The surgeon can dedicate more attention to the operation itself instead of repeated interruptions for myocardial protection. In our practice, we use DN routinely for minimally invasive mitral cases and selectively for full sternotomy cases.

These results are particularly interesting, as they imply that DN may even offer better myocardial protection than traditional multidose cardioplegia. Surgeons may therefore get "more for less" with DN. While DN did not increase survival, decreased bypass and ischemic times have been shown to be independent risk factors for operative mortality. $^{14-16}$ Further study with larger clinical registries is 
needed to determine the effect of DN on patient survival. Moreover, the effectiveness and safety of DN remains to be clearly demonstrated in high-risk patients and those requiring long, complex cases. Optimal redosing strategies must also be determined. Additional laboratory and clinical investigation is therefore warranted.

\section{References}

1. Melrose DG, Dreyer B, Bentall HH, Baker JBE. Elective cardiac arrest. Lancet. 1955;266:21-3.

2. Ad N, Holmes SD, Massimiano PS, Rongione AJ, Fornaresio LM, Fitzgerald D. The use of del Nido cardioplegia in adult cardiac surgery: a prospective randomized trial. J Thorac Cardiovasc Surg. 2018;155:1011-8.

3. Sanetra K, Gerber W, Shrestha R, Domaradzki W, Krzych L, Zembala M, et al The del Nido versus cold blood cardioplegia in aortic valve replacement: a randomized trial. J Thorac Cardiovasc Surg. June 28, 2019 [Epub ahead of print].

4. Braathen B, Jeppsson A, Scherstén H, Hagen OM, Vengen $\varnothing$, Rexius H, et al. One single dose of histidine-tryptophan-ketoglutarate solution gives equally good myocardial protection in elective mitral valve surgery as repetitive cold blood cardioplegia: a prospective randomized study. J Thorac Cardiovasc Surg. 2011;141:995-1001.

5. Chambers DJ, Fallouh HB. Cardioplegia and cardiac surgery: pharmacological arrest and cardioprotection during global ischemia and reperfusion. Pharmacol Ther. 2010;127:41-52.

6. Liu J, Feng Z, Zhao J, Li B, Long C. The myocardial protection of HTK cardioplegic solution on the long-term ischemic period in pediatric heart surgery. ASAIO J. 2008;54:470-3.

7. Ad N, Henry L, Friehling T, Wish M, Holmes SD. Minimally invasive standalone cox-maze procedure for patients with nonparoxysmal atrial fibrillation. Ann Thorac Surg. 2013;96:792-9.
8. Gallandat Huet RCG, Karliczek GF, Homan van der Heide JN, Brenken U, Mooi B, van der Broeke JJ, et al. Clinical effect of Bretschneider-HTK and St. Thomas cardioplegia on hemodynamic performance after bypass measured using an automatic datalogging database system. Thorac Cardiovasc Surg. 1988;36: $151-6$.

9. Demmy TL, Molina JE, Ward HB, Gorton ME, Kouchoukos NT, Schmaltz RA, et al. Custodiol versus Plegisol: a phase 3 multicentre myocardial protection study. Int J Angiol. 2008;17:149-53.

10. Vivacqua A, Robinson J, Abbas AE, Altshuler JM, Shannon FL, Podolsky RH, et al. Single-dose cardioplegia protects myocardium as well as traditional repetitive dosing: a noninferiority randomized study. J Thorac Cardiovasc Surg. May 11, 2019 [Epub ahead of print].

11. Talwar S, Chatterjee S, Sreenivas V, Makhija N, Kapoor PM, Choudhary SK, et al. Comparison of del Nido and histidine-tryptophan-ketoglutarate cardioplegia solutions in pediatric patients undergoing open heart surgery: a prospective randomized clinical trial. J Thorac Cardiovasc Surg. 2019; 157:1182-11892.e1.

12. Gambardella I, Gaudino MF, Antoniou GA, Rahouma M, Worku B, Tranbaugh RF, et al. Single- versus multidose cardioplegia in adult cardiac surgery patients: a meta-analysis. J Thorac Cardiovasc Surg. 2020;160: 1195-202.e12.

13. Kim K, Ball C, Grady P, Mick S. Use of del Nido cardioplegia for adult cardiac surgery at the Cleveland Clinic: perfusion implications. J Extra Corpor Technol. 2014;46:317-23.

14. Nissinen J, Biancari F, Wistbacka JO, Peltola T, Loponen P, Tarkiainen P, et al. Safe time limits of aortic cross-clamping and cardiopulmonary bypass in adult cardiac surgery. Perfusion. 2009;24:297-305.

15. Salis S, Mazzanti VV, Merli G, Salvi L, Tedesco CC, Veglia F, et al. Cardiopulmonary bypass duration is an independent predictor of morbidity and mortality after cardiac surgery. J Cardiothorac Vasc Anesth. 2008;22: 814-22.

16. Ruggieri VG, Bounader K, Verhoye JP, Onorati F, Rubino AS, Gatti G, et al. Prognostic impact of prolonged cross-clamp time in coronary artery bypass grafting. Hear Lung Circ. 2018;27:1476-82. 